21. Mano M. Vinorelbine in the management of breast cancer: new perspectives, revived role in the era of targeted therapy. Cancer Treat Rev 2006; 32: 106-118.

22. Pegram M, Hsu S, Lewis G et al. Inhibitory effects of combinations of HER-2/neu antibody and chemotherapeutic agents used for treatment of human breast cancers. Oncogene 1999; 18: 2241-2251.

23. Pegram MD, Konecny GE, O'Callaghan $\mathrm{C}$ et al. Rational combinations of trastuzumab with chemotherapeutic drugs used in the treatment of breast cancer. J Natl Cancer Inst 2004; 96: 739-749.

24. Chan A. A review of the use of trastuzumab (Herceptin) plus vinorelbine in metastatic breast cancer. Ann Oncol 2007; 18: 1152-1158.

25. Lee YR, Huh SJ, Lee DH et al. Phase II study of vinorelbine plus trastuzumab in HER2 overexpressing metastatic breast cancer pretreated with anthracyclines and taxanes. J Breast Cancer 2011; 14: 140-146.

26. De Maio E, Pacilio C, Gravina A et al. Vinorelbine plus 3-weekly trastuzumab in metastatic breast cancer: a single-centre phase 2 trial. BMC Cancer 2007; 7: 50

27. Papaldo $P$, Fabi A, Ferretti $G$ et al. A phase II study on metastatic breast cancer patients treated with weekly vinorelbine with or without trastuzumab according to HER2 expression: changing the natural history of HER2-positive disease. Ann Oncol 2006; 17: 630-636.

28. Suzuki Y, Tokuda $Y$, Saito $Y$ et al. Combination of trastuzumab and vinorelbine in metastatic breast cancer. Jpn J Clin Oncol 2003; 33: 514-517.

29. Infante JR, Yardley DA, Burris HA, III et al. Phase II trial of weekly docetaxel, vinorelbine, and trastuzumab in the first-line treatment of patients with HER2positive metastatic breast cancer. Clin Breast Cancer 2009; 9: 23-28.

30. Vici P, Di LL, Sergi D et al. A phase II trial of docetaxel and vinorelbine in patients with advanced breast cancer previously treated with anthracyclines. Oncology 2008; 75: 175-181.

31. Wargin WA, Lucas VS. The clinical pharmacokinetics of vinorelbine (Navelbine). Semin Oncol 1994; 21: 21-27.

32. Degardin M, Bonneterre J, Hecquet $B$ et al. Vinorelbine (navelbine) as a salvage treatment for advanced breast cancer. Ann Oncol 1994; 5: 423-426.
33. Fumoleau P, Delgado FM, Delozier T et al. Phase II trial of weekly intravenous vinorelbine in first-line advanced breast cancer chemotherapy. J Clin Oncol 1993; 11: 1245-1252.

34. Garcia-Conde J, Lluch A, Martin M et al. Phase II trial of weekly IV vinorelbine in first-line advanced breast cancer chemotherapy. Ann Oncol 1994; 5: 854-857.

35. Romero A, Rabinovich MG, Vallejo CT et al. Vinorelbine as first-line chemotherapy for metastatic breast carcinoma. J Clin Oncol 1994; 12: 336-341.

36. Vogel C, O'Rourke M, Winer E et al. Vinorelbine as first-line chemotherapy for advanced breast cancer in women 60 years of age or older. Ann Oncol 1999; 10: $397-402$.

37. Heinemann V, Di GD, Vehling-Kaiser $U$ et al A prospective multicenter phase ॥ study of oral and i.v. vinorelbine plus trastuzumab as first-line therapy in HER2-overexpressing metastatic breast cancer. Ann Oncol 2011; 22: 603-608.

38. Redana S, Donadio M, Nole F et al. Trastuzumab with either docetaxel or vinorelbine as first-line treatment for patients with HER2-positive advanced breast cancer: a retrospective comparison. BMC Cancer 2010; 10: 28.

39. Rezai $\mathrm{K}$, Urien $\mathrm{S}$, Isambert $\mathrm{N}$ et al. Pharmacokinetic evaluation of the vinorelbinelapatinib combination in the treatment of breast cancer patients. Cancer Chemother Pharmacol 2011; 68: 1529-1536.

40. Swaby R, Blackwell $K$, Jiang $Z$ et al. Neratinib in combination with trastuzumab for the treatment of advanced breast cancer: a phase I/II study. J Clin Oncol 2009; 27: 1004.

41. Saura C, Martin M, Moroose R et al. Safety of neratinib (HKI-272) in combination with capecitabine in patients with solid tumors: a phase 1/2 study. Presented at 32nd Annual San Antonio Breast Cancer Symposium. San Antonio, TX 9-13 December 2009, Abstract 5108.

42. Chow L, Jiang Z, Epstein R et al. Safety and efficacy of neratinib (HKI-272) in combination with paclitaxel in patients with solid tumors. J Clin Oncol 2009; 27: 160s. Abstract 3557.

43. Gandhi L, Bahleda R, Cleary JM et al. Two-dimensional phase I study of neratinib (NER) combined with temsirolimus (TEM) in patients (Pts) with solid tumors. J Clin Oncol 2011; 29: Abstract 3027.

\title{
Breast cancer management and outcome according to surgeon's affiliation: a population-based comparison adjusted for patient's selection bias
}

\author{
F. Taban¹, E. Rapiti², G. Fioretta², Y. Wespi ${ }^{1}$, D. Weintraub ${ }^{1}$, A. Hugli ${ }^{1}$, H. Schubert², G. Vlastos ${ }^{3}$, \\ M. Castiglione ${ }^{3} \&$ C. Bouchardy ${ }^{2 \star}$ \\ ${ }^{1}$ SONGe (Séno ONcologie Genevoise), Geneva Private Practitioners Breast Cancer Network, Geneva; '²Geneva Cancer Registry, Institute for Social and Preventive \\ Medicine, University of Geneva, Geneva; ${ }^{3}$ Breast Center Unit, Geneva University Hospitals, Geneva, Switzerland
}

Received 27 March 2012; accepted 2 July 2012

Background: Studies have reported that breast cancer (BC) units could increase the quality of care but none has evaluated the efficacy of alternative options such as private BC networks, which is our study objective.

Patients and methods: We included all $1404 \mathrm{BC}$ patients operated in the public unit or the private network and recorded at the Geneva Cancer Registry between 2000 and 2005. We compared quality indicators of care between the

${ }^{*}$ Correspondence to: Prof. C. Bouchardy, Geneva Cancer Registry, Institute for Social and Preventive Medicine, University of Geneva, 55 Boulevard de la Cluse, 1205 Geneva, Switzerland. Tel: +41-22-379-49-50; Fax. +41-22-379-49-71; E-mail: christine.bouchardymagnin@unige.ch 
public BC unit and the private BC network by logistic regression and evaluated the effect of surgeon's affiliation on BC-specific mortality by the Cox model adjusting for the propensity score.

Results: Both the groups had high care quality scores. For invasive cancer, histological assessment before surgery and axillary lymph node dissection when indicated were less frequent in the public sector (adjusted odds ratio (OR): 0.4, 95\% confidence interval (Cl) 0.3-0.7, and OR: 0.4, 95\% $\mathrm{Cl} \mathrm{0.2-0.8,} \mathrm{respectively),} \mathrm{while} \mathrm{radiation} \mathrm{therapy} \mathrm{after}$ breast-conserving surgery was more frequent (OR: 2.5, 95\% Cl 1.4-4.8). Surgeon affiliation had no substantial effect on BC-specific mortality (adjusted hazard ratio (HR): 0.8, 95\% Cl 0.5-1.4).

Conclusions: This study suggests that private $\mathrm{BC}$ networks could be an alternative to public $\mathrm{BC}$ units with both structures presenting high quality indicators of BC care and similar BC-specific mortality.

Key words: breast cancer, network, prognosis, quality of care, unit

\section{introduction}

Breast cancer $(\mathrm{BC})$ management has dramatically changed in the last two decades becoming increasingly complex. BC care requires a comprehensive assessment of multiple tasks needing a multidisciplinary approach. Professional organizations like the European Society of Breast Cancer Specialists (EUSOMA) have issued several recommendations to raise the quality of care of BC patients [1]. Among those, dedicated BC units with multidisciplinary pre-therapeutic meetings are proposed to stimulate professionals to collaborate, to increase their experience, and to continue professional training. Such units have been progressively implemented in Europe with the goal of ensuring high quality standards to all BC patients. In Switzerland, the Swiss Cancer League with the help of professional societies is currently developing guidelines for accreditation of future Swiss BC units [2].

However, the implementation and accreditation of protocols of such units are quite rigid in structure. Although the published literature tends to support the efficacy of such BC units, the level of evidence remains weak [3]. Putative alternative and more flexible options to BC units, such as BC networks of health care professionals, have been created but have never been evaluated in terms of efficacy.

The Swiss canton of Geneva has a particularly high incidence rate of $\mathrm{BC}$, but survival rates are among the highest in Europe $[4,5]$. The canton of Geneva presents also the best survival and quality indicators of BC care in Switzerland [6]. Geneva, with its $\sim 450000$ inhabitants, is essentially urban and provides dense medical resources. The Swiss health care system is based on a federal law called LAMal (voted on 18 March 1994) that consists of a basic health insurance that each individual has to contract. This compulsory insurance covers for everybody universal access to preventive and therapeutic care as well as pharmaceuticals. The costs per person are about 350 Euros per month. The Swiss government covers the complete medical insurance fees for indigent individuals ( $\sim 10 \%$ of the population) and part of the fees for people with low income ( $\sim 17 \%$ of the population). Approximately $25 \%$ of the population contract supplementary health insurance to benefit of care not covered by the compulsory health insurance (i.e. free choice of hospital physicians and superior levels of hospital accommodation).

Approximately $50 \%$ of $\mathrm{BC}$ patients are treated in the private sector. Both the public and private sectors offer an exhaustive range of care covering screening mammography, diagnostic magnetic resonance imaging (MRI), positron emission tomography (PET scan), pathology laboratories to wellequipped operating rooms.

In the public sector, the public $\mathrm{BC}$ unit has established a systematic multidisciplinary consultation meeting weekly to discuss the best therapeutic approaches for all new BC cases referred to the Geneva University Hospitals since 2001. In addition, all cases are rediscussed after the first-line treatments for the proposition of adjuvant treatments and follow-up.

In the private sector, the BC network SONGe (Séno ONcologie Genevoise), found in 2000, regroups most of the private health professionals with particular interest in the field of BC care. This network meets every month to discuss new topics in $\mathrm{BC}$ management in order to reach the highest clinical standards.

Other private practitioners, who are not affiliated to the BC network, are mostly gynecologists and surgeons who also operate BC but are not specialized in BC surgery.

The objective of our study is to compare BC quality of care and outcome between patients operated by surgeons of the public $\mathrm{BC}$ unit and those operated by surgeons of the private BC network after accounting for the biases linked to patients' selection. This study was requested by the BC network to assess the quality of its $\mathrm{BC}$ management.

\section{patients and methods}

\section{patient, tumor and treatment characteristics}

We used data from the Geneva Cancer Registry, which records all incident cancers occurring in the population of the canton. All hospitals, pathology laboratories and practitioners are requested to report all cancer cases. Registrars abstract data from medical and laboratory records. Physicians regularly receive questionnaires to secure missing data. Recorded data include sociodemographic variables, tumor characteristics (coded according to the International Classification of Diseases for Oncology ICD-O), stage at diagnosis (coded according to the TNM Classification of Malignant Tumors), and treatment received within 6 months after diagnosis $[7,8]$.

The Registry regularly assesses survival. The index date refers to the date of confirmation of diagnosis or the date of hospitalization if it precedes the diagnosis and is related to the disease. In addition to passive follow-up (routine examination of death certificates and hospital records), active follow-up is carried out yearly by linking the files of the Cantonal Population Office in charge of the registration of the resident population with the Registry database, using a personal identity number.

The exact cause of death is established by systematically consulting clinical records and/or by inquiring the patient's physician. The cause of 
death is coded according to the international statistical classification of diseases and health-related problems established by the World Health Organization [9].

Among the 2075 women diagnosed with a first primary BC in 20002005 who have undergone surgery for the first treatment, we excluded from the analysis patients operated outside Geneva $(N=63,3.0 \%)$ or by other hospital services other than the public BC unit (i.e. thoracic surgery) $(N=31,1.5 \%)$, and by private surgeon's not affiliated to the private $\mathrm{BC}$ network $(N=577,28 \%)$. The study finally included 1404 BC patients. Patients were followed up for survival until 31 December 2009.

Variables of interest included: age $(<50,50-69,70-79, \geq 80$ years); period of diagnosis (2000-2002, 2003-2005); social class coded according to the last occupation of the woman, and for unemployed, that of the spouse (high, medium, low, unknown); country of birth (Switzerland, Southern Europe, other); family history of breast or ovarian cancer (high: at least one first-degree relative diagnosed with breast or ovarian cancer before the age of 50 years, none: no affected first- or second-degree relative with breast or ovarian cancer, medium: all other known family histories, unknown); method of discovery (mammography screening, clinical screening, breast self-examination, other, unknown); stage coded according to the pathological tumor, node, metastasis (pTNM) classification of malignant tumors (In situ, I, II, III, IV, unknown); pathological surgical tumor size (in $\mathrm{mm}$ ); tumor grade (well, moderately, poorly differentiated, unknown); histology (ductal, lobular, other); estrogen and progesterone receptor status (positive if $\geq 10 \%$ expressed, negative, unknown); human epidermal growth factor receptor 2 (HER2) (positive, negative, unknown); type of surgery (breast-conserving surgery, mastectomy); number of surgeries $(1,>1)$; surgical margins (positive, negative, unknown); sentinel lymph node research (yes, no); axillary lymph node dissection (yes, no); number of lymph nodes removed $(<10$, $\geq 10$ ); radiotherapy (yes, no); chemotherapy (yes, no); and hormonal therapy (yes, no).

\section{surgeon groups}

We divided BC patients into two groups according to the surgeon's affiliation: the public $\mathrm{BC}$ unit and the private $\mathrm{BC}$ network.

The public $\mathrm{BC}$ unit regroups university hospital professionals working in the field of $\mathrm{BC}$ care, i.e. gynecologists, medical oncologists, radio oncologists, plastic surgeons, pathologists, radiologists, social assistants, and specialized BC nurses. These specialists meet on a weekly basis to discuss the best therapeutic options for each newly diagnosed $\mathrm{BC}$ patient. For the majority of patients, one meeting is sufficient. If supplementary investigations are needed, the multidisciplinary team refers the final pretherapeutic decision to a second meeting. When the patient has undergone the first-line treatments, her files are reviewed again to propose the best adjuvant treatment and follow-up.

The private $\mathrm{BC}$ network meets monthly to discuss advances in $\mathrm{BC}$ treatment and research. This private network regroups all professionals in the private sector with particular interest in $\mathrm{BC}$ care including gynecologists, medical oncologists, radio oncologists, plastic surgeons, pathologists, and radiologists. Affiliation to the private BC network has progressively been strengthened and membership criteria include experience in $\mathrm{BC}$ diagnosis and treatment, participation in international congresses and/or presentations in national or local congresses in their field. Every 2 years, the network organizes a symposium on the latest standards for BC guidelines and controversies. Contrary to the public BC unit, $\mathrm{BC}$ patients are not systematically presented to the other members of the network. Instead, the multidisciplinary work-up is tailored according to the situation of the patient and left to the appreciation of the first specialist who treated the patient.

\section{indicators of quality of care}

We a priori defined state of the art treatment according to the quality indicators set by the EUSOMA [10]. We selected indicators which could be determined from our Registry database.

For in situ cancer, we retained the following quality indicators: (i) reporting of tumor size and grade; (ii) histological assessment before surgery; (iii) a single operation for the primary tumor (excluding reconstruction); (iv) negative surgical margin; (v) lack of axillary lymph node dissection; (vi) breast-conserving surgery for tumor $\leq 2 \mathrm{~cm}$; and (vii) radiotherapy after breast-conserving surgery. The last indicator does not appear in the EUSOMA guidelines but was built on the basis of the last Cochrane review on postoperative radiotherapy for ductal carcinoma in situ of the breast [11].

For invasive cancer, we considered the following indicators: (i) reporting of tumor size, grading, and estrogens receptor status; (ii), (iii), and (iv) the same as for in situ cancer; (v) sentinel lymph node biopsy for clinically negative axilla; (vi) axillary lymph node dissection when the lymp node is clinically (physically and/or by imaging) suspect of metastasis or positive lymph node sentinel biopsy; (vii) at least 10 lymph nodes removed when axillary dissection was carried out; (viii) breast-conserving surgery for tumor $\leq 3 \mathrm{~cm}$; (ix) radiotherapy after breast-conserving surgery if no metastasis; $(\mathrm{x})$ radiotherapy after mastectomy for $\mathrm{pT} 3$ or $\mathrm{pT} 4$ or positive margin or $\geq \mathrm{pN} 2 \mathrm{a}$; (xi) endocrine therapy for estrogen receptor-positive tumors; and (xii) chemotherapy for estrogen receptor-negative tumors $>1$ $\mathrm{cm}$ or $N$ positive or age $\leq 35$ years. Each indicator was scored 1 when correctly carried out, 0 otherwise. Indicators were scored only if the item was applicable to the patient.

We developed one overall score of good practice for in situ using the seven items and one for invasive cancer using the twelve items. The overall score obtained by dividing the sum of the values attained at the pertinent items by the total number of pertinent items multiplied by 100. For example, in the presence of a patient with a $5 \mathrm{~cm}$ in situ tumor with no mention of tumor grade in the pathological report, with histological assessment before surgery, with two operations for the primary tumor, with negative margins, without axillary lymph node dissection, and mastectomy, the score calculation is as follows: item $1=0$, item $2=1$, item $3=0$, item $4=1$, item $5=1$, item $6=$ not pertinent, and item $7=$ not pertinent; the sum is 3 , divided by 5 pertinent items $=60 \%$.

\section{statistical analysis}

We compared patient and tumor characteristics between the two groups of surgeons by $\chi^{2}$ test. We also evaluated the differences in the quality of diagnosis and treatment by logistic regression, considering as cases women operated by surgeons affiliated to the public $\mathrm{BC}$ unit, and as controls those operated by surgeons of the private $\mathrm{BC}$ network. We evaluated the effect of surgeon's affiliation on BC-specific mortality by Cox models. To account for the bias related to the selection of patients, i.e. the nonrandom assignment to the surgeon's group, we adjusted all analyses by the propensity score [12]. To build the propensity score, we identified by logistic regression substantial sociodemographic differences between the surgeon groups and derived a continuous variable which predicted the individual probability to be treated by one of the two groups.

We considered differences to be statistically significant at $P$ value $<0.05$ and used SPSS software (Version 14; SPSS Inc, Chicago, IL, USA).

\section{results}

\section{patient, and tumor characteristics according to surgeon's affiliation}

Of the 1404 patients, 166 had in situ and 1238 invasive BC. Surgeons of the public BC unit operated $50 \%(N=83)$ of the 
in situ cancer patients and $60.7 \%(N=752)$ of the patients with invasive tumors. Patient and tumor characteristics are presented in Table 1 for in situ cancer and Table 2 for invasive cancer. For in situ cancer, when compared with women operated in the private $\mathrm{BC}$ network, women operated by a surgeon of the public BC unit were of lower social class, had less frequently tumor detected by mammography screening, had more often a report on tumor grade, and presented more frequently a tumor with non-ductal histology (Table 1). In the logistic regression model, two variables, i.e. period of diagnosis and social class, were retained by the logistic regression model to build the propensity score.

For invasive cancer, patients treated by surgeons from the public BC unit were older, of lower social class, were more often born in Southern Europe, and had less often tumor detected by screening. For other remaining variables such as familial history, tumor characteristics (including stage, hormone receptor status, and grade), there were no differences among the surgeon groups. In fact, the only substantial difference was the lower proportion of unknown data for patients treated by public BC unit surgeons compared with those treated by surgeons of the private BC network (Table 2). In the logistic regression model, the propensity score was built on age, country of birth, and social class.

\section{score of quality of care according to surgeon's affiliation}

Tables 3 and 4 show the distribution of quality indicators between the two surgeon groups for in situ and invasive cancer, respectively. The tables also present the $P$ values of the $\chi^{2}$ tests and the odds ratios (OR) derived from the logistic regression adjusted for the propensity scores (right columns).

For in situ cancer, the mean score of care quality (based on the seven relevant items) was high in each group: $82 \%$ for the public $\mathrm{BC}$ unit and $78 \%$ for the private $\mathrm{BC}$ network $(P=$ 0.132 ). Only two indicators were substantially different between the public BC unit and the private BC network. Higher report of in situ tumor size and grading was observed for women operated by the public BC unit surgeons [69\% versus $42 \%$, OR adjusted for the propensity score for the public $\mathrm{BC}$ unit versus private $\mathrm{BC}$ network: $3.0,95 \%$ confidence interval (CI): $1.5-5.8, P=0.001]$. Conversely, the public BC unit surgeons carried out less frequently breast-conserving surgery when indicated than surgeons in the private $\mathrm{BC}$ network (65\% versus $90 \%$, OR: $0.3,95 \%$ CI $0.1-0.9, P=0.030$ ). We observed no differences for other indicators.

For invasive cancer, the mean score of quality (based on twelve items) was high with a slight but significant difference in favor of patients treated by the surgeons of the private $\mathrm{BC}$ network ( $85 \%$ for the public BC unit and $87 \%$ for the private $\mathrm{BC}$ network; $P=0.007)$. Significant differences existed between the two groups concerning the histological assessment before surgery, which was not reported in $13 \%$ of the public BC unit patient files compared with only $6 \%$ in the private $\mathrm{BC}$ network (OR: $0.4,95 \%$ CI $0.3-0.7, P<0.000$ ). The use of axillary lymph node dissection when indicated was lower in the public BC unit than in the private BC network (85\% versus $94 \%$, OR: 0.4 , $95 \%$ CI $0.2-0.8, P=0.018)$. Radiation therapy after breast- conserving surgery was more frequently carried out for patients operated by the public BC unit surgeons than those operated by the private BC network surgeons ( $96 \%$ versus $93 \%$, OR: $2.5,95 \%$ CI $1.3-4.8, P=0.004)$. The use of tamoxifen, when indicated, tended to be more frequent in the public BC unit than in the private BC network. The opposite was observed for the use of chemotherapy. However, the last two results were not significant in adjusted analysis.

\section{breast cancer BC-specific mortality according to surgeon's affiliation}

The mean follow-up of patients with invasive cancer was 6.3 years and 67 women died from BC during the study follow-up.

Table 5 presents the effect of surgeon's affiliation on BCspecific mortality among patients with invasive BC. Hazard ratios (HRs) were adjusted for propensity scores. The surgeon's affiliation had no substantial effect on BC-specific mortality (adjusted HR for women operated by surgeons of the BC network when compared with those operated by surgeons of the public BC unit: $0.8,95 \%$ CI 0.5-1.4). Additional adjustment for tumor characteristics (including stage, grade, and tumor receptors) did not modify the result.

\section{discussion}

Although there is some scientific evidence that dedicated BC units with multidisciplinary tumor boards increases the quality of care, we have no data evaluating the effectiveness of other approaches [13]. We evaluated whether the quality of care differed between patients treated by surgeons affiliated to the public $\mathrm{BC}$ unit and those treated by surgeon members of the private $\mathrm{BC}$ network, accounting for patient's selection bias to provide interpretable comparison. We found that the quality of care of the two approaches is high and very close.

Furthermore, BC-specific mortality is similar between the two surgeon groups.

For in situ cancer, differences in quality indicators between the public $\mathrm{BC}$ unit and the private $\mathrm{BC}$ network were mainly linked to the higher report rate of in situ tumor size and grading for women operated in the public BC unit. This result is due to coding differences between pathologists at the Geneva University Hospitals and those of the private sector. The latter frequently describe cancer grade as 'low/medium' or 'medium/ high', making it difficult for registrars to recode data according to the three levels (low, medium, and high) grading classification of disease in oncology used by cancer registries. On the contrary, for women with small tumors, the public BC unit surgeons tended to perform breast-conserving surgery less frequently than surgeons of the private $\mathrm{BC}$ network.

For invasive cancer, the histological assessment before surgery was less frequently carried out for patients operated by the public BC unit surgeons, with $\sim 10 \%$ of women operated on the basis of cytological evaluation only. Axillary dissection, when indicated, was less frequently carried out by surgeons from the public BC unit, with approximately one-third of the patients not having dissection. On the contrary, radiation therapy after breast-conserving surgery was less frequently 
Table 1. Patient, tumor, and treatment characteristics according to surgeon's affiliation among patients with in situ breast cancer

\begin{tabular}{|c|c|c|c|}
\hline & \multicolumn{2}{|l|}{ Surgeon's affiliation } & \multirow{2}{*}{$\begin{array}{l}P \text { value for } \\
\text { heterogeneity test }{ }^{\mathrm{a}}\end{array}$} \\
\hline & $\begin{array}{l}\text { Public BC unit } \\
{[N(\%) ; 83(50.0)]}\end{array}$ & $\begin{array}{l}\text { Private BC network } \\
{[N(\%) ; 83(50.0)]}\end{array}$ & \\
\hline Mean age at diagnosis (years) & 57.5 & 57.3 & 0.942 \\
\hline Age & & & 0.238 \\
\hline$<50$ & $21(25.3)$ & $15(18.1)$ & \\
\hline $50-69$ & $48(57.8)$ & $60(72.3)$ & \\
\hline $70-79$ & $11(13.3)$ & $7(8.4)$ & \\
\hline$\geq 80$ & $3(3.6)$ & $1(1.2)$ & \\
\hline \multicolumn{4}{|l|}{ Period of diagnosis } \\
\hline 2000-2002 & $44(53.0)$ & $32(38.6)$ & 0.086 \\
\hline 2003-2005 & $39(47.0)$ & $51(61.4)$ & \\
\hline \multicolumn{4}{|l|}{ Social class } \\
\hline High & $16(20.3)$ & $23(28.0)$ & 0.004 \\
\hline Medium & $47(59.5)$ & $56(68.3)$ & \\
\hline Low & $16(20.3)$ & $3(3.7)$ & \\
\hline Unknown & $4(-)$ & $1(-)$ & \\
\hline \multicolumn{4}{|l|}{ Country of birth } \\
\hline Switzerland & $42(50.6)$ & $47(56.6)$ & 0.059 \\
\hline Southern Europe & $23(27.7)$ & $11(13.3)$ & \\
\hline Other & $18(21.7)$ & $25(30.1)$ & \\
\hline \multicolumn{4}{|l|}{ Method of detection } \\
\hline Mammography screening & $57(68.7)$ & $67(82.7)$ & 0.005 \\
\hline Clinical screening & $1(1.2)$ & $3(3.7)$ & \\
\hline Breast self-palpation & $5(6.0)$ & $7(8.6)$ & \\
\hline Other & $20(24.1)$ & $4(4.9)$ & \\
\hline Unknown & - & $2(-)$ & \\
\hline \multicolumn{4}{|l|}{ Familial history of $\mathrm{BC}$} \\
\hline High & $9(10.8)$ & $9(11.5)$ & 0.808 \\
\hline Medium & $16(19.3)$ & $12(15.4)$ & \\
\hline None & $58(69.9)$ & $57(73.1)$ & \\
\hline Unknown & - & $5(-)$ & \\
\hline \multicolumn{4}{|l|}{ Grade } \\
\hline Well differentiated & $15(20.5)$ & $9(22.0)$ & 0.999 \\
\hline Other & $58(79.5)$ & $32(78.0)$ & \\
\hline Unknown & $10(-)$ & $42(-)$ & \\
\hline \multicolumn{4}{|l|}{ Histology } \\
\hline Ductal & $77(92.8)$ & $83(100.0)$ & 0.044 \\
\hline Lobular & $5(6.0)$ & - & \\
\hline Other & $1(1.2)$ & - & \\
\hline \multicolumn{4}{|l|}{ Estrogen receptor status } \\
\hline Positive & $66(89.2)$ & $59(79.7)$ & 0.173 \\
\hline Negative & $8(10.8)$ & $15(20.3)$ & \\
\hline Unknown & $9(-)$ & $9(1-)$ & \\
\hline \multicolumn{4}{|l|}{ Progesterone receptor status } \\
\hline Positive & $53(71.6)$ & $41(55.4)$ & 0.060 \\
\hline Negative & $21(28.4)$ & $33(44.6)$ & \\
\hline Unknown & $9(-)$ & $9(-)$ & \\
\hline \multicolumn{4}{|l|}{ Her2 receptor status ${ }^{\mathrm{b}}$} \\
\hline Positive & $9(64.3)$ & $3(42.9)$ & 0.397 \\
\hline Negative & $5(35.7)$ & $4(57.1)$ & \\
\hline Unknown & $69(-)$ & $76(-)$ & \\
\hline
\end{tabular}

${ }^{\mathrm{a}}$ After exclusion of unknown data.

bince 2001.

BC, breast cancer; HER2, human epidermal growth factor receptor 2. 
Table 2. Patient, tumor, and treatment characteristics according to surgeon's affiliation among patients with invasive breast cancer

\begin{tabular}{|c|c|c|c|}
\hline & \multicolumn{2}{|l|}{ Surgeon's affiliation } & \multirow{2}{*}{$\begin{array}{l}P \text { value for } \\
\text { heterogeneity test }\end{array}$} \\
\hline & $\begin{array}{l}\text { Public BC unit } \\
{[N(\%) ; 752(60.7)]}\end{array}$ & $\begin{array}{l}\text { Private BC network } \\
{[N(\%) ; 486(39.3)]}\end{array}$ & \\
\hline Mean age at diagnosis (years) & 61.8 & 58.8 & $<0.001$ \\
\hline \multicolumn{4}{|l|}{ Age } \\
\hline$<50$ & $141(18.8)$ & $101(20.8)$ & \multirow[t]{4}{*}{$<0.001$} \\
\hline $50-69$ & $394(52.4)$ & $306(63.0)$ & \\
\hline $70-79$ & $150(19.9)$ & $61(12.6)$ & \\
\hline$\geq 80$ & $67(8.9)$ & $18(3.7)$ & \\
\hline \multicolumn{4}{|l|}{ Period of diagnosis } \\
\hline 2000-2002 & $350(46.5)$ & $237(48.8)$ & \multirow[t]{2}{*}{0.449} \\
\hline $2003-2005$ & $402(53.5)$ & $249(51.2)$ & \\
\hline \multicolumn{4}{|l|}{ Social class } \\
\hline High & $90(12.3)$ & $137(28.8)$ & \multirow[t]{4}{*}{$<0.001$} \\
\hline Medium & $427(58.3)$ & $295(62.1)$ & \\
\hline Low & $215(29.4)$ & $43(9.1)$ & \\
\hline Unknown & $20(-)$ & $11(-)$ & \\
\hline \multicolumn{4}{|l|}{ Country of birth } \\
\hline Switzerland & $362(48.1)$ & $254(52.3)$ & \multirow[t]{3}{*}{$<0.001$} \\
\hline Southern Europe & $258(34.3)$ & $96(19.8)$ & \\
\hline Other & $132(17.6)$ & $136(28.0)$ & \\
\hline \multicolumn{4}{|l|}{ Method of detection } \\
\hline Mammography screening & $290(38.6)$ & $201(42.1)$ & \multirow[t]{5}{*}{0.016} \\
\hline Clinical screening & $67(8.9)$ & $63(13.2)$ & \\
\hline Breast self-palpation & $288(38.3)$ & $163(34.2)$ & \\
\hline Other & $106(14.1)$ & $50(10.5)$ & \\
\hline Unknown & $1(-)$ & $9(-)$ & \\
\hline \multicolumn{4}{|l|}{ Familial history of BC } \\
\hline High & $68(9.1)$ & $31(6.8)$ & \multirow[t]{4}{*}{0.125} \\
\hline Medium & $173(23.2)$ & $126(27.5)$ & \\
\hline None & $505(67.7)$ & $302(65.8)$ & \\
\hline Unknown & $6(-)$ & $27(-)$ & \\
\hline \multicolumn{4}{|l|}{ Stage } \\
\hline I & $389(52.2)$ & $236(50.3)$ & \multirow[t]{5}{*}{0.475} \\
\hline II & $301(40.4)$ & $206(43.9)$ & \\
\hline III & $51(6.8)$ & $24(5.1)$ & \\
\hline IV & $4(0.5)$ & $3(0.6)$ & \\
\hline Unknown & $7(-)$ & $17(-)$ & \\
\hline \multicolumn{4}{|l|}{ Lymph node invasion } \\
\hline No & $517(69.1)$ & $317(67.7)$ & \multirow[t]{3}{*}{0.612} \\
\hline Yes & $231(30.9)$ & $151(32.3)$ & \\
\hline Unknown & $4(-)$ & $18(-)$ & \\
\hline \multicolumn{4}{|l|}{ Grade } \\
\hline Well differentiated & $250(34.1)$ & $161(33.8)$ & 0.950 \\
\hline Other & $404(65.9)$ & $220(66.2)$ & \\
\hline Unknown & $18(-)$ & $9(-)$ & \\
\hline Histology & & & \\
\hline Ductal & $612(81.4)$ & $399(82.1)$ & 0.853 \\
\hline Lobular & $109(14.5)$ & $70(14.4)$ & \\
\hline Other & $31(4.1)$ & $17(3.5)$ & \\
\hline Estrogen receptor status & & & \\
\hline Positive & $652(86.8)$ & $429(89.6)$ & 0.179 \\
\hline Negative & $99(13.2)$ & $50(10.4)$ & \\
\hline Unknown & $1(-)$ & $7(-)$ & \\
\hline Progesterone receptor status & & & \\
\hline Positive & $552(73.5)$ & $354(73.9)$ & 0.895 \\
\hline Negative & $199(26.5)$ & $125(26.1)$ & \\
\hline Unknown & $1(-)$ & $7(-)$ & \\
\hline
\end{tabular}


Table 2. Continued

\begin{tabular}{|c|c|c|c|}
\hline & \multicolumn{2}{|l|}{ Surgeon's affiliation } & \multirow{2}{*}{$\begin{array}{l}P \text { value for } \\
\text { heterogeneity test }\end{array}$} \\
\hline & $\begin{array}{l}\text { Public BC unit } \\
{[N(\%) ; 752(60.7)]}\end{array}$ & $\begin{array}{l}\text { Private BC network } \\
{[N(\%) ; 486(39.3)]}\end{array}$ & \\
\hline \multicolumn{4}{|c|}{ HER2 receptors ${ }^{\mathrm{b}}$} \\
\hline Positive & $135(24.8)$ & $65(25.4)$ & \multirow[t]{3}{*}{0.861} \\
\hline Negative & $409(75.2)$ & $191(74.6)$ & \\
\hline Unknown & $208(-)$ & $230(-)$ & \\
\hline
\end{tabular}

${ }^{\mathrm{a}}$ After exclusion of unknown data.

${ }^{\mathrm{b}}$ Recorded since 2001 .

BC, breast cancer; HER2, human epidermal growth factor receptor 2.

Table 3. Quality of diagnosis assessment and treatment according to surgeon's affiliation among patients with in situ breast cancer

\begin{tabular}{|c|c|c|c|c|c|}
\hline Indicator of quality & $\begin{array}{l}\text { Public BC unit } \\
{[N(\%) ; 83(50.0)]}\end{array}$ & $\begin{array}{l}\text { Private BC network } \\
{[N(\%) ; 83(50.0)]}\end{array}$ & $\begin{array}{l}P \text { value for } \\
\text { heterogeneity }\end{array}$ & $\begin{array}{l}\text { Propensity score adjusted } \\
\text { odds ratio (OR) comparing } \\
\text { public unit versus } \\
\text { private network OR }(95 \% \mathrm{CI})\end{array}$ & $\begin{array}{l}P \text { value of logistic } \\
\text { regression }\end{array}$ \\
\hline \multicolumn{6}{|l|}{ Reporting of tumor size and grading } \\
\hline Yes & $57(68.7)$ & $35(42.2)$ & 0.001 & 1 (reference) & 0.001 \\
\hline No & $26(31.3)$ & $48(57.8)$ & & $3.0(1.5-5.8)$ & \\
\hline \multicolumn{6}{|c|}{ Histological assessment before surgery } \\
\hline Yes & $69(83.1)$ & $62(74.7)$ & 0.253 & 1 (reference) & 0.170 \\
\hline No & $14(16.9)$ & $21(25.3)$ & & $1.8(0.8-3.9)$ & \\
\hline \multicolumn{6}{|l|}{ Number of interventions } \\
\hline One & $71(85.5)$ & $66(79.5)$ & 0.414 & 1 (reference) & 0.607 \\
\hline More & $12(14.5)$ & $17(20.5)$ & & $1.3(0.5-2.9)$ & \\
\hline \multicolumn{6}{|l|}{ Surgical margins } \\
\hline Negative & 77 (93.9) & $80(96.4)$ & 0.496 & 1 (reference) & 0.359 \\
\hline Positive & $5(6.1)$ & $3(3.6)$ & & $0.5(0.1-2.3)$ & \\
\hline Unknown & $1(-)$ & - & & & \\
\hline \multicolumn{6}{|l|}{ Axillary dissection } \\
\hline No & $73(88.0)$ & $75(90.4)$ & 0.804 & 1 (reference) & 0.842 \\
\hline Yes & $10(12.0)$ & $8(9.6)$ & & $1.1(0.4-3.3)$ & \\
\hline \multicolumn{6}{|c|}{ Breast-conserving surgery for tumor $\leq 20 \mathrm{~mm}$} \\
\hline Yes & $32(65.3)$ & $44(89.8)$ & 0.007 & 1 (reference) & 0.030 \\
\hline No & $17(34.3)$ & $5(10.2)$ & & $0.3(0.1-0.9)$ & \\
\hline$>20 \mathrm{~mm}$ or NOS not requested & $34(-)$ & $34(-)$ & & & \\
\hline \multicolumn{6}{|c|}{ Radiotherapy after breast-conserving surgery } \\
\hline Yes & $41(89.1)$ & $54(83.1)$ & 0.423 & 1 (reference) & 0.413 \\
\hline No & $5(10.9)$ & $11(16.9)$ & & $1.6(0.5-5.2)$ & \\
\hline Not pertinent (mastectomy) & $37(-)$ & $18(-)$ & & & \\
\hline \multicolumn{6}{|l|}{ Score of care quality } \\
\hline$\leq 75 \%$ & $60(72.3)$ & $46(55.4)$ & 0.035 & 1 (reference) & \\
\hline$>75 \%$ & $23(27.7)$ & $37(44.6)$ & & $2.3(1.1-4.5)$ & 0.021 \\
\hline Mean score of quality & 81.7 & 77.8 & 0.132 & & \\
\hline
\end{tabular}

BC, breast cancer.

delivered to patients treated in the private $\mathrm{BC}$ network than in the public BC unit.

Reviews on the effect of multidisciplinary care on BC survival in particular, or more generally on all types of cancers conclude that although intrinsically multidisciplinary care should be associated with better survival, there is little evidence to support this $[3,14]$. Great disparities exist in study designs and in the definition of multidisciplinary approaches. This also applies for studies on BC units. Some studies have considered the specialization, others the membership of a professional society (association), the affiliation to a specialized center, the hospital or the surgeon's caseload. One cohort study on almost 30000 operated BC patients in the Los Angeles County has reported that treatment by a surgical oncologist compared with 
Table 4. Quality of diagnosis assessment and treatment according to surgeon's affiliation among patients with invasive breast cancer

\begin{tabular}{|c|c|c|c|c|c|}
\hline Indicator of quality & $\begin{array}{l}\text { Public BC unit } \\
{[N(\%) ; 752(60.7)]}\end{array}$ & $\begin{array}{l}\text { Private BC network } \\
{[N(\%) ; 486(39.3)]}\end{array}$ & $P$ value for heterogeneity & $\begin{array}{l}\text { Propensity score adjusted } \\
\text { odds ratio (OR) comparing public } \\
\text { unit versus private network } \\
\text { OR }(95 \% \mathrm{CI})\end{array}$ & $\begin{array}{l}P \text { value of logistic } \\
\text { regression }\end{array}$ \\
\hline \multicolumn{6}{|c|}{ Reporting of hormone receptor, tumor size, and grading } \\
\hline Yes & $719(95.6)$ & $470(96.7)$ & \multirow[t]{2}{*}{0.373} & 1 (reference) & \multirow[t]{2}{*}{0.351} \\
\hline No & $33(4.4)$ & $16(3.3)$ & & $0.7(0.4-1.4)$ & \\
\hline \multicolumn{6}{|c|}{ Histological assessment before surgery } \\
\hline Yes & $652(86.7)$ & $456(93.8)$ & \multirow[t]{2}{*}{$<0.001$} & 1 (reference) & \multirow[t]{2}{*}{$<0.001$} \\
\hline No & $100(13.3)$ & $30(6.2)$ & & $0.4(0.3-0.7)$ & \\
\hline \multicolumn{6}{|l|}{ Number of interventions } \\
\hline One & $651(86.6)$ & $401(82.5)$ & \multirow[t]{2}{*}{0.061} & 1 (reference) & \multirow[t]{2}{*}{0.148} \\
\hline More & $101(13.4)$ & $85(17.5)$ & & $1.3(0.9-1.8)$ & \\
\hline \multicolumn{6}{|l|}{ Surgical margins } \\
\hline Negative & $679(90.9)$ & $455(93.8)$ & \multirow{3}{*}{0.068} & 1 (reference) & \multirow{3}{*}{0.080} \\
\hline Positive & $68(9.1)$ & $30(6.2)$ & & $0.7(0.4-1.1)$ & \\
\hline Unknown & $5(-)$ & $1(-)$ & & excluded & \\
\hline \multicolumn{6}{|c|}{ Sentinel lymph node if indicated ${ }^{\mathrm{a}}$} \\
\hline Yes & $368(69.7)$ & $254(73.2)$ & \multirow[t]{3}{*}{0.286} & 1 (reference) & \multirow[t]{3}{*}{0.679} \\
\hline No & $160(30.3)$ & $93(26.8)$ & & $0.9(0.7-1.3)$ & \\
\hline Not pertinent & $224(-)$ & $139(-)$ & & excluded & \\
\hline \multicolumn{6}{|c|}{ Axillary dissection when indicated ${ }^{\mathrm{a}}$} \\
\hline Yes & $187(85.4)$ & $127(94.1)$ & \multirow[t]{3}{*}{0.015} & 1 (reference) & \multirow[t]{3}{*}{0.018} \\
\hline No & $32(14.6)$ & $8(5.9)$ & & $0.4(0.2-0.8)$ & \\
\hline Not pertinent & $533(-)$ & $351(-)$ & & excluded & \\
\hline \multicolumn{6}{|c|}{ Number of lymph nodes removed } \\
\hline$\geq 10$ & $281(75.9)$ & $186(75.0)$ & 0.849 & 1 (reference) & 0.798 \\
\hline$<10$ & $89(24.1)$ & $62(25.0)$ & & $1.1(0.7-1.6)$ & \\
\hline Not pertinent & $382(-)$ & $238(-)$ & & excluded & \\
\hline Breast-conserving surgery $\mathrm{v}$ & vhen indicated ${ }^{\mathrm{a}}$ & & & & \\
\hline Yes & $518(79.2)$ & $366(84.3)$ & 0.039 & 1 (reference) & 0.105 \\
\hline No & $136(20.8)$ & $68(15.7)$ & & $0.8(0.5-1.1)$ & \\
\hline Not pertinent & $98(-)$ & $52(-)$ & & excluded & \\
\hline Breast-conserving surgery a & nd radiotherapy & & & & \\
\hline Yes & $534(96.4)$ & $353(92.9)$ & 0.022 & 1 (reference) & 0.004 \\
\hline No & $20(3.6)$ & $27(7.1)$ & & $2.5(1.4-4.8)$ & \\
\hline Not pertinent & $198(-)$ & $106(-)$ & & excluded & \\
\hline Mastectomy and radiothera & py when indicated ${ }^{\mathrm{a}}$ & & & & \\
\hline Yes & $11(44.0)$ & $7(70.0)$ & 0.264 & 1 (reference) & 0.314 \\
\hline No & $14(56.0)$ & $3(30.0)$ & & $0.4(0.1-2.2)$ & \\
\hline Not pertinent & $727(-)$ & $476(-)$ & & excluded & \\
\hline Anti-estrogen use when ind & icated $^{\mathrm{a}}$ & & & & \\
\hline Yes & $611(93.7)$ & $390(90.9)$ & 0.096 & 1 (reference) & 0.084 \\
\hline No & $41(6.3)$ & $39(9.1)$ & & $1.5(0.9-2.5)$ & \\
\hline Not pertinent & $100(-)$ & $57(-)$ & & excluded & \\
\hline Chemotherapy use when in & dicated $^{\mathrm{a}}$ & & & & \\
\hline Yes & $164(56.0)$ & $131(72.0)$ & $<0.001$ & 1 (reference) & 0.082 \\
\hline No & $129(44.0)$ & $51(28.0)$ & & $0.7(0.5-1.1)$ & \\
\hline Not pertinent & $459(-)$ & $304(-)$ & & excluded & \\
\hline Score of care quality & & & & & \\
\hline$<50 \%$ & $24(3.2)$ & $15(3.1)$ & 0.030 & & \\
\hline$<75 \%$ & $172(22.9)$ & $86(17.7)$ & & & \\
\hline$<90 \%$ & $291(38.7)$ & $176(36.2)$ & & & \\
\hline$>90-100 \%$ & $265(35.2)$ & $209(43.0)$ & & & \\
\hline Score of care quality & & & & & \\
\hline$\leq 75 \%$ & $196(26.1)$ & $101(20.8)$ & 0.035 & 1 (reference) & 0.220 \\
\hline$>75 \%$ & $556(73.9)$ & $385(79.2)$ & & $0.8(0.6-1.1)$ & \\
\hline Mean score of care quality & 85.0 & 87.3 & 0.007 & & \\
\hline
\end{tabular}

${ }^{\mathrm{a}}$ See the patients and methods section.

$\mathrm{BC}$, breast cancer. 
Table 5. Effect of surgeon's affiliation on breast cancer specific mortality

\begin{tabular}{lcc} 
Surgeon's affiliation & $\begin{array}{c}\text { Crude hazard ratio } \\
\text { (HR; 95\% CI) }\end{array}$ & $\begin{array}{l}\text { HR adjusted for } \\
\text { propensity scores (95\% CI) }\end{array}$ \\
Public BC unit & 1 (reference) & 1 (reference) \\
Private BC network & $0.7(0.4-1.2)$ & $0.8(0.5-1.4)$ \\
\hline
\end{tabular}

$\mathrm{BC}$, breast cancer.

a non-specialist surgeon resulted in a $33 \%$ reduction in the risk of death at 5 years in multivariate analysis, while treatment at a specialist center did not affect survival [15]. A significant increase in survival was also observed in a population-based cohort of 2192 patients in Oklahoma city for patients operated by specialist surgeons versus non-specialists. This study also reported differences in the use of adjuvant therapy, type of surgery, and compliance to treatment between specialized and non-specialized surgeons [16]. In Scotland, a retrospective study of 3786 patients reported a $16 \%$ of decreased mortality after adjustment for age, tumor size, socioeconomic status, and nodal involvement in BC patients cared for by specialist surgeons [17]. Another study including 24834 patients from the Florida Cancer Data System reported higher survival rates for patients treated at teaching hospitals compared with community or low-volume hospitals $[18,19]$. The authors concluded that many of these differences were due to the decreased use of proven adjuvant therapies, underlining the need for an integrated treatment for this disease. In Norway, where nearly all BC patients are treated in public hospitals, breast units with multidisciplinary meetings have been introduced in a staggered fashion along with a screening program since 1996. A cohort study of 1131 patients with resectable $\mathrm{BC}$ reported that relapse-free survival and overall survival did not differ substantially between the hospital groups based on the surgical workload or between university and nonuniversity hospitals [20].

As previously reported, the quality of $\mathrm{BC}$ care is high in Switzerland [21]. This study reported that multidisciplinary therapeutic discussion was associated with substantially higher average quality of care, higher surgical sub-score and higher nonsurgical sub-score. The article also shows that BC patients treated in the canton of Geneva had the highest mean and surgical quality of care scores. The high degree of compliance with $\mathrm{BC}$ care recommendations found in the canton of Geneva was remarkable. As possible explanation, the authors of the study evoked the fact that in Geneva, most of the predictors of high management score are present: high caseload and clinical research at the Geneva University Hospitals, together with a higher proportion of patients with tertiary education, income in the highest tertile, and living in an urban area with high accessibility to specialized care. Our study results showing high scores for both the public BC unit and the private BC network contribute to explain the overall good performance observed in Geneva.

In our study, we found few differences in the quality of care and no differences in survival between the public $\mathrm{BC}$ unit and the private $\mathrm{BC}$ network. This could be linked to the fact that sophisticated medical tools are widely available in the public as well as in the private sector. Such tools include mammography, ultrasound, MRI, PET scan, good operating theaters with experienced pathologists in BC in both sectors of care. As seen at the Geneva University Hospitals, numerous private oncologists and gynecologists in the canton working as breast surgeons attend international breast conferences, meet regularly to update their knowledge, and discuss patient's medical files. Another particularity of the medical system in Geneva is that nearly $50 \%$ of the cancer patients are treated in the private sector. A total of 1981 BC patients were operated in the canton during the study period. Among those, 1146 (58\%) were operated by private surgeons (i.e. $569,29 \%$ by those affiliated to the BC network and $577,29 \%$ by other private surgeons), a situation very different from other parts in the world [22].

As expected, our study shows that the public BC unit, considered as the reference for the public sector in the canton, served more disadvantaged patients with higher proportions of elderly, low social class, and foreign patients. Despite that, the quality of care of the public BC unit remains high. On the other hand, the added value for a patient to remain within her doctor's caring referees, as it is probably more often the case in the private $\mathrm{BC}$ network. This, although not easily computable, could be important for many patients [23].

The main limitations of our study are linked to its observational nature, as it is the case of all previous studies because of the lack of clinical trials testing BC units or network efficacy. In our study, patients treated by the public BC unit and the private $\mathrm{BC}$ network are not similar in terms of age, social class, and nationality. These sociodemographic variables, in particular age and social class, can strongly affect BC quality of care and outcome $[24,25]$. To minimize the selection bias of BC patients' recruitment between surgeons groups, we adjusted all analyses for the propensity score. This has never been carried out before. We cannot, however, exclude the residual selection effect from unrecorded variables, such as patient co-morbidities, or other factors linked to the patient's status, social context, or behavior. Analysis by age sub-groups $(<50,50-70, \geq 71$ years $)$, to indirectly account for the increasing presence of co-morbidities with advancing age, did not change the results presented on the quality scores but only on the levels of significance due to the lowered power. Also, the results from survival analysis should be considered as preliminary because of the short follow-up and the few events (i.e. cancer deaths) linked to high BC survival. Also, the definitions we use for our $\mathrm{BC}$ unit and network correspond to specific daily practice of $\mathrm{BC}$ care in the canton of Geneva, the public $\mathrm{BC}$ unit has not yet been formally accredited as defined by the EUSOMA 'Requirements of a specialist breast unit 2010'. This unit responds to most, but not all, necessary criteria issued. It includes all BC specialists, an important caseload, a weekly multidisciplinary medical pre-therapeutic and post-operative discussion of nearly all newly diagnosed patients in the public sector, and centralized medical facilities including specific radio-diagnostic and radiotherapy. The private $\mathrm{BC}$ network's work is more informal with no pretherapeutic systematic discussion and medical facilities are not centralized in one institution. Therefore, the results presented in our study could not be easily extrapolated in other contexts. 
Also, the way of collecting data on treatments between the public and private sectors differed with direct access to hospital files for the public sector and through specific questionnaires for the private sector. However, this could influence the recording of later use of adjuvant treatments but not surgery or radiotherapy, as the registry recorded similarly and directly the data from pathological and radiotherapy reports from both the sectors. Finally, this study did not consider the costs or the patient's satisfaction which are important indicators of the care system evaluation.

The strength of our study is the use the quality indicators of care developed specifically for accreditation of BC units by EUSOMA, which will allow future comparisons with other studies [10]. We are, however, aware of the fact that these indicators are not all linked to prognosis (such as use of breastconserving surgery for small tumors) but are more linked to the quality of life. We could not study all the recommended indicators, including those concerning the evaluation of overtreatment or breast reconstruction, because part of the information needed to construct such indicators was lacking during the time of this study. Another strength of our study is the determination of exact cause of death by trained registrars from medical files and inquiries to physicians which offer a unique opportunity to assess correctly true BC-specific mortality.

In conclusion, in Geneva, the quality of $\mathrm{BC}$ care is high in both the public BC unit and the private BC network. Similarly operating networks could be considered as a less stringent alternative of BC units after careful evaluation of their efficacy. Finally, despite high quality of care, there is still rule for both improvement and homogenization of $\mathrm{BC}$ treatment between the private and public sectors.

\section{acknowledgements}

We thank Milena Uehlinger for her technical and editorial assistance, and the Geneva Cancer Registry team for providing data and support.

\section{disclosure}

The authors have declared no conflicts of interest.

\section{references}

1. EUSOMA. The requirements of a specialist breast unit. http://www.eusoma.org/ Engx/BreastUnits/Guideline.aspx?cont=breast. (1 March 2012, date last accessed).

2. Swiss Cancer League. http://www.liguecancer.ch/fr/. (16 March 2012, date last accessed).

3. Houssami N, Sainsbury R. Breast cancer: multidisciplinary care and clinical outcomes. Eur J Cancer 2006; 42: 2480-2491.
4. Boyle P, Levin B (eds). World Cancer Report. Lyon: International Agency for Research on Cancer (IARC), 2008.

5. Sant M, Allemani C, Santaquilani M et al. EUROCARE-4. Survival of cancer patients diagnosed in 1995-1999. Results and commentary. Eur J Cancer 2009; 45: 931-991.

6. Fisch $\mathrm{T}$, Pury $\mathrm{P}$, Probst $\mathrm{N}$ et al. Variation in survival after diagnosis of breast cancer in Switzerland. Ann Oncol 2005; 16: 1882-1888.

7. Fritz A, Percy C, Jack A et al. (eds). ICD-0 International Classification of Diseases for Oncology, 3rd edition. Geneva: World Health Organization (WHO), 2000.

8. Sobin LH, Wittekind Ch. (eds). TNM Classification of Malignant Tumours, 6th edition. New York: Wiley-Liss, 2002.

9. World Health Organization. ICD-10. International Statistical Classification of Diseases and Health Related Problems, 10th revision. Geneva: World Health Organization, 1992.

10. Del Turco MR, Ponti A, Bick U et al. Quality indicators in breast cancer care. Eur J Cancer 2010; 46: 2344-2356.

11. Goodwin A, Parker S, Ghersi D et al. Post-operative radiotherapy for ductal carcinoma in situ of the breast. Cochrane Database Syst Rev 2009 0ct 7; (4): CD000563.

12. Rubin DB. Estimating causal effects from large data sets using propensity scores. Ann Intern Med 1997; 127: 757-763.

13. Newman $E A$, Guest $A B$, Helvie MA et al. Changes in surgical management resulting from case review at a breast cancer multidisciplinary tumor board. Cancer 2006; 107: 2346-2351.

14. Hong NJ, Wright FC, Gagliardi AR et al. Examining the potential relationship between multidisciplinary cancer care and patient survival: an international literature review. J Surg Oncol 2010; 102: 125-134.

15. Skinner KA, Helsper JT, Deapen D et al. Breast cancer: do specialists make a difference? Ann Surg Oncol 2003; 10: 606-615.

16. Dooley WC, Bong J, Parker J. Mechanisms of improved outcomes for breast cancer between surgical oncologists and general surgeons. Ann Surg Oncol 2011; 18: 3248-3251.

17. Gillis CR, Hole DJ. Survival outcome of care by specialist surgeons in breast cancer: a study of 3786 patients in the west of Scotland. BMJ 1996; 312: 145-148.

18. Guller U, Safford S, Pietrobon R et al. High hospital volume is associated with better outcomes for breast cancer surgery: analysis of 233,247 patients. World $\mathrm{J}$ Surg 2005; 29: 994-999.

19. Gutierrez JC, Hurley JD, Housri N et al. Are many community hospitals undertreating breast cancer? Lessons from 24,834 patients. Ann Surg 2008; 248: 154-162.

20. Fjosne HE, Soreide JA, Karesen $\mathrm{R}$ et al. Hospital volume and prognosis among Norwegian breast cancer patients enrolled in adjuvant trials. Acta Oncol 2011; 50: 1068-1074.

21. Ess $\mathrm{S}$, Savidan A, Frick $\mathrm{H}$ et al. Geographic variation in breast cancer care in Switzerland. Cancer Epidemiol 2010; 34: 116-121.

22. Kalager $\mathrm{M}$, Zelen $\mathrm{M}$, Langmark $\mathrm{F}$ et al. Effect of screening mammography on breast-cancer mortality in Norway. N Engl J Med 2010; 363: 1203-1210.

23. Bouche G, Migeot V, Mathoulin-Pelissier $\mathrm{S}$ et al. Breast cancer surgery: do all patients want to go to high-volume hospitals? Surgery 2008; 143: 699-705.

24. Bouchardy C, Rapiti E, Fioretta $G$ et al. Undertreatment strongly decreases prognosis of breast cancer in elderly women. J Clin Oncol 2003; 21: 3580-3587.

25. Bouchardy C, Verkooijen HM, Fioretta G. Social class is an important and independent prognostic factor of breast cancer mortality. Int J Cancer 2006; 119: 1145-1151. 